\section{Stress Distribution in Roots Restored with Fiber Posts and An Experimental Dentin Post: 3D-FEA}

Hugo Henrique Diana, Juliana Santos Oliveira, Mariana Carolina de Lara Ferro, Yara T. Corrêa Silva-Sousa, Érica Alves Gomes
School of Dentistry, University of Ribeirão Preto, Ribeirão Preto, SP, Brazil

Correspondance: Profa. Dra. Érica Alves Gomes, Avenida Costábile Romano, 2201, 14096-900, Ribeirão Preto, SP, Brazil. Tel: +55-16-3603-7000. E-mail: ericaagomes@yahoo.com.br

\begin{abstract}
The aim of this study was to compare the stress distribution in radicular dentin of a maxillary canine restored with either a glass fiber post, carbon fiber post or an experimental dentin post using finite element analysis (3D-FEA). Three 3D virtual models of a maxillary canine restored with a metal-ceramic crown and glass fiber post (GFP), carbon fiber post (CFP), and experimental dentin post (DP) were obtained based on micro-CT images. A total of $180 \mathrm{~N}$ was applied on the lingual surface of the incisal third of each tooth at 45 degrees. The models were supported by the periodontal ligament fixed in three axes $(x=y=z=0)$. The von Mises stress (VMS) of radicular dentin and the intracanal posts was calculated. The structures of all groups showed similar values (MPa) and distribution of maximum von Mises stress. Higher stress was found in the apical third of dentin while the posts presented homogeneous stress distribution along the axis. The fiber and dentin posts exhibited similar stress values and distribution. Thus, the experimental dentin post is a promising restorative material.
\end{abstract}

(1)

\author{
Key Words: posts, techniques \\ of intracanal retainer, elastic \\ modulus, finite element analysis
}

\section{Introduction}

Endodontically treated teeth are more prone to root fragility, fractures and exodontia as a consequence of tooth destruction and collagen alteration (1). Therefore, studies have been performed to develop a restorative material with physical and mechanical properties similar to dentin for rehabilitation of endodontically treated teeth (2).

Prefabricated fiber posts embedded in a resin matrix have been suggested as a promising restorative material that presents appropriate esthetics and biocompatibility. These posts are easy to use and show an elastic modulus similar to human dentin, which favors stress distribution along the root axis (3). Thus, glass and carbon fiber posts have been widely used for oral rehabilitation $(1,2,4)$. However, a failure rate of up to $7 \%$ is still reported for treatments with these intracanal retainers (5).

Dentin has a complex microstructure and simulation of its biomechanical properties remains a challenge. Some researchers have used human teeth for the fabrication of an intracanal retainer, referred to as a "dentin post" $(2,6,7)$. Recent studies have suggested that a dentin post enhances stability and adhesion, which reduces the risk of fracture of endodontically treated teeth $(2,6)$. However, additional studies are necessary for biomechanical evaluation of this material and standardization of the technique for professional use.

The finite element analysis (FEA) is a numerical method that uses a virtual model to evaluate complex mechanical problems. Several materials can be evaluated with this low-cost method through simulation of clinical scenarios without using human teeth and/or testing in patients (8).

The aim of this study was to evaluate the stress distribution in radicular dentin and an intracanal post of a maxillary canine restored with either a carbon fiber post, glass fiber post or an experimental human dentin post using three-dimensional finite element analysis (3D-FEA). The null hypothesis assumed no difference in stress distribution among the groups.

\section{Material and Methods}

The study was approved by the Research Ethics Committee (C.A.A.E.: 22249113.7.0000.5498). A sound maxillary canine with $15.0 \mathrm{~mm}$ of root length was used to fabricate the models.

Three 3D finite element models were obtained to represent an endodontically treated maxillary canine supported by the periodontal ligament and restored with a metal-ceramic crown and different intracanal retainers. Three groups tested were: Group GFP: glass fiber post, Group CFP: carbon fiber post, and Group DP: dentin post.

\section{Fabrication of Finite Element Model}

The 3D geometry of the sound canine and its characteristics were obtained using micro computed tomography (micro-CT) (SkyScan 1174v2; Bruker-microCT, Kontich, Belgium). A total of 994 transverse sections were obtained with $0.5 \mathrm{~mm}$ slices along the tooth. The microCT data was transferred to a 3D image converter software 
(Simpleware 4.1, Simpleware Ltd, Rennes Drive, Exeter, United Kingdom) for segmentation and fabrication of the masks based on the pixel density to generate the 3D solid model of the groups. A $0.2 \mathrm{~mm}$ thick periodontal ligament was included in all 3D models (Fig. 1A) (9).

CAD structures were simulated as real clinical procedures in a CAD software (SolidWorks 2007, SolidWorks Corp., Concord, MA, USA) to represent endodontic treatment and prosthetic rehabilitation. The images were transferred by the software Simpleware 4.1 (Simpleware Ltd), for processing the groups through Boolean addition and subtraction.

In all models, a working length of $14.0 \mathrm{~mm}-1.0 \mathrm{~mm}$ short of the radicular apex - was simulated with canal instrumentation up to a \#50 file and sealing with guttapercha. The root canal was restored with parallel-sided posts with a $1.5 \mathrm{~mm}$ diameter and $14.0 \mathrm{~mm}$ length. A total of 4.0 $\mathrm{mm}$ of gutta-percha was preserved at the apical region. The cementation line presented a $50.0 \mu \mathrm{m}$ thickness.

A composite resin core for crown restoration was simulated with reduction of $1.0 \mathrm{~mm}$ on the buccal and lingual surfaces and $2.0 \mathrm{~mm}$ on the incisal edge. A metalceramic crown was also designed, including a metallic coping with $0.5 \mathrm{~mm}$ thickness veneered with feldspathic

s porcelain with $0.5 \mathrm{~mm}$ thickness on the buccal and lingual surfaces and $1.5 \mathrm{~mm}$ on the incisal edge (Fig. 1B).

\section{Mechanical Properties of the Materials (Elastic Modulus [E] and Poisson's Ratio [v])}

The elastic modulus and Poisson's ratio of some structures were determined using the impulse excitation technique (Sonelastic, ATCP Engenharia Física, Ribeirão Preto, SP, Brazil) because there is a wide range of values in the literature for different materials and commercial brands. Thus, specimens of the following materials were tested: 1 - composite resin (Z250; 3M/ESPE, St Paul, MN, USA) for the core, 2 - resin cement (Rely $X_{i} 3 \mathrm{M} / \mathrm{ESPE}$ ) for post cementation, 3 - Ni-Cr alloy (Vera Bond II, AalbaDent. Inc., USA) of the metal-ceramic crown coping, and 4 pressable porcelain (IPS InLine PoM, Ivoclar Vivadent AG, Schaan, Liechtenstein, Germany) for the metal-ceramic crown veneer. Three specimens with a $4.0 \mathrm{~mm}$ width, 2.0 $\mathrm{mm}$ height and $25.0 \mathrm{~mm}$ length were fabricated for each material, according to the manufacturer's instructions.

The samples were positioned on a specific device for application of a short-time impact using a pulsator, generating mechanical vibrations. A transducer captured the acoustic response and transformed it into an electrical signal so that the resonance frequencies could be read. A specimen designed as a rectangular bar, according to the manufacturer's instructions, was tested to calculate the elastic modulus by bending excitation and Poisson's ration by torsion excitation. The steps were repeated in each sample until a non-significant difference ( $2 \%$ or less) was observed between the last and the current value measured.

The mechanical properties of the materials ( $E$ and $v$ ) (Tables 1-3) were transferred to the software Simpleware 4.1, based on literature data (10-13) and the values calculated by the impulse excitation technique. All materials were assumed to be homogeneous, isotropic and linearly elastic; except for the glass and carbon fiber posts that were assumed as orthotropic, homogenous and linearly elastic. A complete joint between all structures of the model was simulated.

\section{Generation of Finite Element Mesh}

The finite element mesh was obtained using linear tetrahedral elements, type C3D4. The models presented 234,824 nodes and 1,243,290 elements. Mesh refining was based on a convergence analysis of 6\%.

\section{Definition of Boundary And Loading Conditions}

The finite element mesh of each model was imported by the finite element software (Abaqus 6.10-EF1, Dassault Systèmes Simulus Corp., Providence, RI, USA) for simulation of static loading of $180 \mathrm{~N}$ on the lingual surface of the incisal third of the tooth at 45 degrees in all models. The nodes of the periodontal ligament were fixed in the three Cartesian axes ( $x, y$ and $z$ ), assuming $x=y=z=0$ (Fig. 1C).

The results were calculated with the finite element software using stress maps (hot colors represent higher stress while cold colors represent lower stress) and numerical analysis. The value of maximum von Mises stress (VMS) was obtained after loading.

\section{Results}

Similar values (MPa) and distribution of maximum von Mises stress were observed in all groups (Fig. 1D). Table 4 shows the VMS values for the intracanal posts and radicular dentin in all groups. Higher stresses were observed in the pressable porcelain, especially at the loading area. In the radicular dentin, higher stresses were found in the apical third; but it was distributed along the proximal surfaces in all groups. Intracanal posts showed homogeneous stress distribution along the axis with a slight increase in stress at the apical region.

\section{Discussion}

Restoration of endodontically treated teeth remains a challenge due to a higher risk of biomechanical failure as a consequence of significant tooth destruction (1), coronal and/or root caries, extensive restoration, occlusal imbalance, and preparation for intracanal retainers. Intracanal posts are required to provide retention of the restoration. However, an intracanal restoration may concentrate forces 
in the root, depending on post type and material (3). The aim of this study was to evaluate stress distribution in the radicular dentin of a maxillary canine restored with different intracanal posts (glass fiber post, carbon fiber post, and experimental dentin posts) using 3D-FEA. The results confirmed the null hypothesis, which assumed no difference among the post materials.

The stresses may occur as tensile, compressive, shear, or a

Table 1. Mechanical properties of materials

\begin{tabular}{lccc}
\hline Material & E (GPa) & $v$ & Reference \\
\hline $\begin{array}{l}\text { Resin cement } \\
\text { (Rely X, 3M/ESPE) }\end{array}$ & 11.54 & 0.24 & Excitation technique \\
$\begin{array}{l}\text { Composite resin } \\
\text { (Z250, 3M/ESPE) }\end{array}$ & 19.16 & 0.54 & Excitation technique \\
$\begin{array}{l}\text { Metallic coping } \\
\text { (Vera Bond II) }\end{array}$ & 209.20 & 0.24 & Excitation technique \\
$\begin{array}{l}\text { Pressable porcelain } \\
\text { (IPS InLine PoM) }\end{array}$ & 73.19 & 0.4 & Excitation technique \\
$\begin{array}{l}\text { Dentin } \\
\begin{array}{l}\text { Periodontal } \\
\text { ligament }\end{array}\end{array}$ & 18.6 & 0.31 & 10 \\
Gutta-percha & $1.4 \times 10^{-1}$ & 0.45 & 10 \\
Dentin post & 18.6 & 0.31 & 11 \\
\hline
\end{tabular}

Table 3. Orthotropic mechanical properties of carbon fiber post

\begin{tabular}{lccc}
\hline $\mathrm{E}$ (GPa) & $v$ & Shear modulus (GPa) & Reference \\
\hline $\mathrm{X}=125$ & $\mathrm{Xy}=0.25$ & $\mathrm{Gxy}=3.1$ & \\
$\mathrm{Y}=8.5$ & $\mathrm{Xz}=0.017$ & $\mathrm{Gxz}=3.0$ & 13 \\
$\mathrm{Z}=8.5$ & $\mathrm{Yz}=0.32$ & $\mathrm{Gyz}=3.1$ & \\
\hline
\end{tabular}
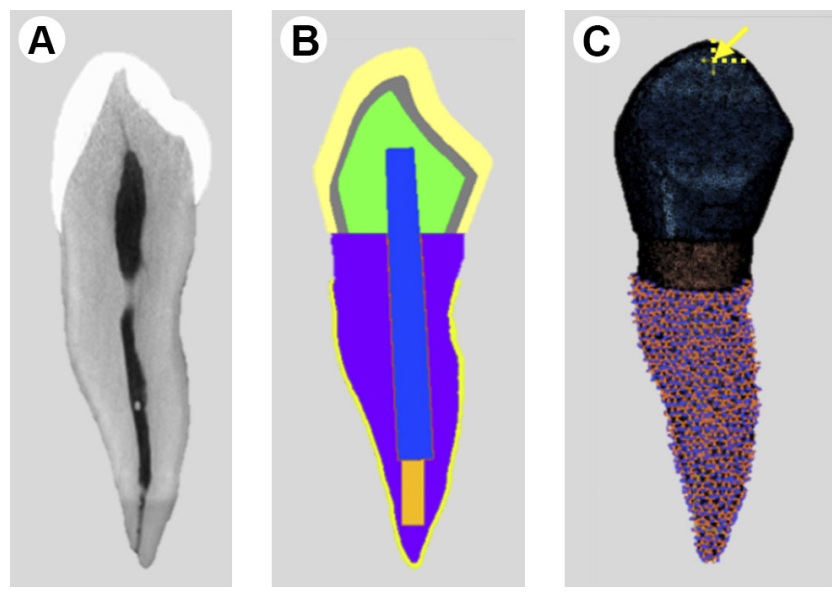

stress combination known as equivalent von Mises stresses. The von Mises stresses are widely used as an indicator of the possibility of damages $(3,9)$. Once the compressive strength of the dentin is considerably greater than the tensile strength, the von Mises stress can be compared with the tensile strength of dentin to assess the risk of fracture. Thus, von Mises stress was chosen for the presentation of the results of this study.

It has been suggested that a dentin post would provide bending similar to the natural tooth, absorb more impacts, and transfer lower stress to the radicular dentin (7). However, in the present study, the dentin post exhibited stress values and distribution similar to the glass and carbon fiber posts. Assuming that the elastic modulus of posts, core and resin cement were similar to the radicular dentin; the stress was homogeneously distributed and supported the whole structure as a monoblock assembly (9).

Table 2. Orthotropic mechanical properties of glass fiber post

\begin{tabular}{cccc}
\hline $\mathrm{E}(\mathrm{GPa})$ & $\mathrm{v}$ & Shear modulus $(\mathrm{GPa})$ & Reference \\
\hline $\mathrm{X}=37$ & $\mathrm{Xy}=0.27$ & $\mathrm{Gxy}=3.1$ & \\
$\mathrm{Y}=9.5$ & $\mathrm{Xz}=0.34$ & $\mathrm{Gxz}=3.5$ & 13 \\
$\mathrm{Z}=9.5$ & $\mathrm{Yz}=0.27$ & $\mathrm{Gyz}=3.1$ & \\
\hline
\end{tabular}

Table 4. Maximum von Mises stress (VMS) for each group

\begin{tabular}{lccc}
\hline \multirow{2}{*}{ Material } & \multicolumn{3}{c}{ Groups } \\
\cline { 2 - 4 } & GFP & CFP & DP \\
\hline Posts & 0.51 & 0.75 & 0.71 \\
Radicular dentin & 1.97 & 1.97 & 1.97 \\
\hline
\end{tabular}

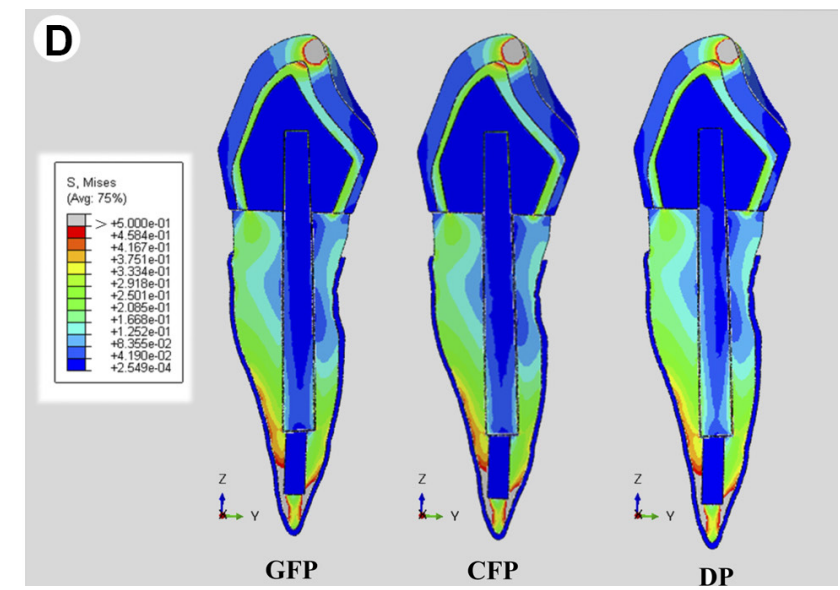

Figure 1. A: Micro computed tomography of sound canine; B: 2D representation of the virtual model; C: 3-D virtual model showing boundary conditions, loading and finite element mesh. The yellow arrow shows the loading point while the periodontal ligament exhibits the restriction conditions of the model; D: VMS stress (MPa) distribution in all groups. Colors indicate the levels from low (dark blue) to high (red) stress. 
Ex vivo materials are widely used for oral rehabilitation in Dentistry. In Implantology, deproteinized bovine bone is used to correct bone defects surrounding implants while fractured teeth can be fixed for restoration in Restorative Dentistry. In this sense, a dentin post obtained from the human dentin of a bulky extracted tooth (i.e. canine) has been suggested as an alternative for the fabrication of intracanal retainers.

The current literature shows positive characteristics for dentin posts, including physical properties similar to radicular dentin (i.e. elastic modulus, viscoelastic performance, compressive strength, and thermal expansion) $(2,6,14)$. Dentin posts have also presented higher fracture strength and favorable fracture patterns under static and dynamic loading when compared to fiber posts, in addition to appropriate bonding at the post-cement-dentin interface (2).

The dentin post can be fabricated using a CAD/CAM system (2), or through reduction of dentin with diamond drills to obtain the appropriate design (6). The human teeth used for fabricating the dentin post must be sterilized using gamma radiation (15) or autoclaved at $121{ }^{\circ} \mathrm{C}$ for 15 min (6), according to infection control protocol, while also $\vec{s}$ presenting minimum alteration of the dentin properties. The dentin posts can be a viable alternative for restorations for low-income people as it is a low-cost and simple technique when compared to fiber posts (14).

However, there is a lack of scientific information regarding the reliable use of a dentin post as an intracanal retainer. In the present study, the dentin post did not show a better biomechanical performance when compared to fiber posts. As a consequence, fiber posts remain the most common material used for fast and effective restoration of endodontically treated teeth; as the exhibit high longterm success rates and the possibility of restoration in the case of failure (4).

Tooth fracture is classified according to further possibility of tooth restoration. A favorable fracture pattern would include horizontal or oblique fractures up to the cervical third and bone level. Catastrophic fractures occur in the apical region and result in exodontia. Previous studies have shown that fiber posts are an appropriate restorative material because they may cause a restorable fracture pattern with a reliable prognosis in case of failure $(3,5)$.

In the present study, the stress concentration in the proximal surfaces was found at the medium and cervical buccal thirds. However, high stress concentration was observed in the apical third of radicular dentin, especially in the region opposite the loading. It is known that oblique forces increase the intensity and concentration of tensile stress at the area opposite of loading due to the metalceramic crown rigidity and tooth bending. Furthermore, the association of the tapered anatomy of the root canal and the parallel design of an intracanal post increases stress in the apical region (16).

Different mechanical properties of the materials are found in the literature depending on commercial brands, year of fabrication, and serial numbers. Considering this uncertainty and its influence on finite element results, the values of elastic modulus and Poisson's ratio of some materials (i.e. resin cement, composite resin core, $\mathrm{Ni}-\mathrm{Cr}$ copping, and porcelain) were determined using the impulse excitation technique to provide a more realistic simulation in the present study.

The present results showed the biomechanical performance of teeth restored with three types of intracanal posts, but careful interpretation of data should be conducted. Although the virtual model was fabricated according to micro-CT data, a reliable method widely used in the current literature, in vitro validation of the models was not conducted in the present study. However, the determination of material properties would enhance the reliability of data obtained in this analysis.

The fiber and dentin posts presented a similar biomechanical performance. Thus, the dentin post is a promising restorative material for rehabilitating endodontically treated teeth. Clinical extrapolation of the results must be done judiciously and prudently, since the finite element analysis is a mathematical methodology and all conditions of the oral environment cannot be simulated. Further analyses are required to demonstrate the superiority of the dentin post with regards to fracture and bonding strengths under static and cyclic loading. In addition, other in vitro and clinical experiments should be conducted to determine the safe and efficient use of dentin posts for restoring endodontically treated teeth.

\section{Resumo}

O objetivo deste estudo foi comparar a distribuição das tensões na dentina radicular de um canino superior restaurado com um pino de fibra de vidro, pino de fibra de carbono ou um pino experimental de dentina por meio do método dos elementos finitos tridimensional (MEF-3D). Três modelos virtuais 3D de um canino superior restaurado com coroa metaloce-râmica e pino de fibra de vidro (PFV), pino de fibra de carbono (PFC) e pino experimental de dentina (PD) foram obtidos baseados em imagens de micro-CT. Uma carga total de $180 \mathrm{~N}$ foi aplicada na superfície lingual do terço incisal de cada dente a 45 graus. 0 s modelos foram suportados pelo ligamento periodontal fixado em três eixos $(x=y=z=0)$. Tensões equivalentes de von Mises (VMS) da dentina radicular e dos pinos intraradiculares foram calculadas. As estruturas de todos os grupos mostraram similar valor (MPa) e distribuição máxima de tensão de von Mises. Elevadas tensões foram encontradas no terço apical da dentina enquanto os pi-nos mostraram distribuição de tensões homogênea em seu longo eixo. Os pinos de fibra e de dentina apresentaram similar valor e distribuição de tensão. Assim, o pino experimental de dentina é um material reabilitador promissor.

\section{Acknowledgements}

The authors wish to thank the supported by Research Grant No. 
2013/23905-9 from Fundação de Amparo à Pesquisa do Estado de São Paulo (FAPESP); the Laboratory of Biomechanical Studies in Prosthodontics and Implants at the Department of Dental Materials and Prosthodontics of FORP-USP, and Endodontics Research Laboratory at the Department of Restorative Dentistry of FORP-USP for technical support.

\section{References}

1. Chuang FS, Yaman P, Herrero A, Dennison BJ, Chang HC. Influence of post material and length on endodontically treated incisors: $A n$ in vitro and finite element study. J Prosthet Dent 2010;104:379-388.

2. Ambica $K$, Mahendran $K$, Talwar S, Verma M, Padmini G, Periasamy R. Comparative evaluation of fracture resistance under static and fatigue loading of endodontically treated teeth restored with carbon fiber posts, glass fiber posts, and an experimental dentin post system: an in vitro study. J Endod 2013;39:96-100.

3. Santos-Filho PC, Veríssimo C, Soares PV, Saltarelo RC, Soares CJ, Marcondes Martins LR. Influence of ferrule, post system, and legth on biomechanical behavior of endodontically treated anterior teeth. J Endod 2014;40:119-23.

4. Goracci C, Ferrari M. Current perspectives on post systems: a literature review. Aust Dent J 2011;56 Suppl 1:77-83.

5. Bitter K, Noetzel J, Stamm 0, Vaudt J, Meyer-Lueckel H, Neumann K, et al. Randomized clinical trial comparing the effects of post placement on failure rate of post endodontic restorations: Preliminary results of a mean period of 32 months. J Endod 2009;35:1477-1482.

6. Alcântara CE, Corrêa-Faria P, Vasconcellos WA, Ramos-Jorge ML. Combined technique with dentin post reinforcement and original fragment reattachment for the esthetic recovery of a fractured anterior tooth: a case report. Dent Traumatol 2010;26:447-450.

7. Martelli R. Fourth-generation intraradicular posts for the aesthetic restoration of anterior teeth. Pract Periodontics Aesthet Dent
2000;12:579-84

8. Oliveira JS, Chaves CAL, Silva-Sousa YTC, Gomes EA. The finite element methods on oral rehabilitation: New trend for endodontically treated teeth. Braz Dent Sci 2014;17:11-18.

9. Gomes EA, Gueleri DB, Silva SR, Ribeiro RF, Silva-Sousa YT. Threedimensional finite element analysis of endodontically treated teeth with weakened radicular walls restored with different protocols. J Prosthet Dent 2015;114:383-389.

10. Reinhardt RA, Krejci RF, Pao YC, Stannard JG. Dentin stresses in post-reconstructed teeth with diminishing bone support. J Dent Res 1983;62:1002-1008.

11. Friedman CM, Sandrik JL, Heuer MA, Rapp GW. Composition and mechanical properties of gutta-percha endodontic points. J Dent Res 1975;54:921-925.

12. Holmes DC, Diaz-Arnold AM, Leary JM. Influence of post dimension on stress distribution in dentin. J Prosthet Dent 1996;75:140-147.

13. Pegoretti A, Fambri L, Zappini G, Bianchetti M. Finite element analysis of a glass fibre reinforced composite endodontic post. Biomaterials 2002;23:2667-2682.

14. Corrêa-Faria P, Alcântara CE, Caldas-Diniz MV, Botelho AM, Tavano KT "Biological restoration": root canal and coronal reconstruction. J Esthet Restor Dent 2010;22:168-178.

15. Brauer DS, Saeki K, Hilton JF, Marshall GW, Marshall SJ. Effect of sterilization by gamma radiation on nano-mechanical properties of teeth. Dent Mater 2008;24:1137-1140.

16. Kishen A. Mechanisms and risk factors for fracture predilection in endodontically treated teeth. Endod Top 2006;13:47-83.

Received November 26, 2015 Accepted March 9, 2016 